Annales Geophysicae (2003) 21:237-250 (C) European Geosciences Union 2003

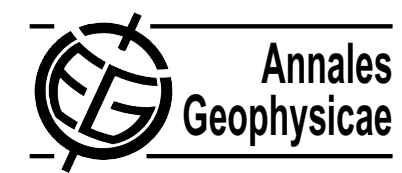

\title{
Assessing the phenomenology of the Cretan Sea shelf area using coupling modelling techniques
}

\author{
G. Triantafyllou ${ }^{1}$, G. Korres ${ }^{2}$, G. Petihakis ${ }^{1}$, A. Pollani ${ }^{1}$, and A. Lascaratos ${ }^{2}$ \\ ${ }^{1}$ Institute of Marine Biology of Crete, P.O.Box 2214, Iraklio, 71003 Crete, Greece \\ ${ }^{2}$ University of Athens, Department of Applied Physics, Oceanography Group, University Campus, Bld. PHYS-V, 15784 \\ Athens, Greece
}

Received: 6 July 2001 - Revised: 6 May 2002 - Accepted: 4 June 2002

\begin{abstract}
In this work the ability of nesting two hydrodynamical models, the high-resolution Cretan Sea shelf model and the lower resolution regional ALERMO model, was investigated. A new database was developed by objectively analysing raw climatological data from the MODB database enriched with in situ measurements collected by the Institute of Marine Biology of Crete. Prior to nesting with the ALERMO model, the Cretan Sea model was integrated using this new hydrological database, in order to investigate the capability of the model setup to describe the phenomenology of the Cretan Sea. Results show that the model can successfully reproduce the complex general circulation characteristics of the area, such as the dipole of a cyclone and an anticyclone, and the flow reversal between winter and summer. As a next step, the shelf-model was one-way nested with the ALERMO model and was integrated on a climatological basis. The evolution of the circulation characteristics of the Cretan Sea was compared, qualitatively and quantitatively, against the results of the regional model, and proved that the nesting between the two models can provide reliable information while overcoming at the same time the computational constraints imposed by high-resolution models.
\end{abstract}

Key words. Oceanography: general (continental shelf processes; numerical modelling) - Oceanography: physical (general circulation)

\section{Introduction}

The Cretan Sea is the largest and deepest basin in the south Aegean Sea, bounded to the north by the Cyclades plateau at the isobath of $400 \mathrm{~m}$, and to the south by the Cretan Arc Islands (Fig. 1a). Its communication with the Levantine and the Ionian Seas takes place through the Cretan Arc Straits. An average depth of $1000 \mathrm{~m}$ and two deeper troughs in the eastern part, 2561 and $2295 \mathrm{~m}$ deep, comprises the main topographic features of the Cretan Sea.

Correspondence to: G. Triantafyllou (gt@imbc.gr)
Several scientific projects, covering a much wider area with emphasis on the Cretan Sea (POEM, Theocharis et al., 1993; MTP-PELAGOS, Balopoulos et al., 1996; CINCS, Georgopoulos et al., 2000), provided important information and advanced our knowledge on the hydrodynamics of the region, suggesting an interannual variability and a significant contribution of the Cretan Sea to the deep layer structure of the eastern Mediterranean.

As revealed by the above-mentioned projects, the hydrological structure of the basin is complex, characterized by mesoscale spatial and temporal variability, which is not necessarily seasonal. The main circulation features are an anticyclone in the central to west part and a cyclone in the eastern part of the region (Theocharis et al., 1999), while other rather transient eddies contribute to the complex circulation pattern. The two main gyres seem to be present in the area for the whole year, but their exact position, shape and intensity change seasonally. Meandering currents and jets without well-defined time scales interconnect the gyres.

The presence of five distinct water masses constitutes the hydrological picture in the Cretan Sea. Less saline Modified Atlantic Water (MAW) (38.7-38.8 psu), along with saline local surface water, share the surface and subsurface layers to a depth of $70 \mathrm{~m}$. MAW is carried by the Mid-Mediterranean Jet (MMJ) within the surface and sub-surface layers from the western Ionian, and enters the Cretan Sea mainly through the southern part of Antikithira and occasionally through the Kassos Straits. Following an eastward route it spreads along the northern coasts of Crete, becoming saltier as it mixes with more saline waters until it disappears. During the winter period its signature may disappear due to the intense vertical mixing. Below MAW and down to a depth of $100 \mathrm{~m}$ the Cretan Intermediate Water (CIW) can be identified over the entire area by its subsurface salinity maximum (exceeding $39.1 \mathrm{psu}$ ). It is formed locally in the Cretan Sea and is slightly warmer and saltier than its underlying Levantine Intermediate Water (LIW), which has with core salinity and temperature values of $38.9-39.1 \mathrm{psu}$ and $14.7-16.9^{\circ} \mathrm{C}$, respectively, and is observed to a depth of $600 \mathrm{~m}$. LIW is 

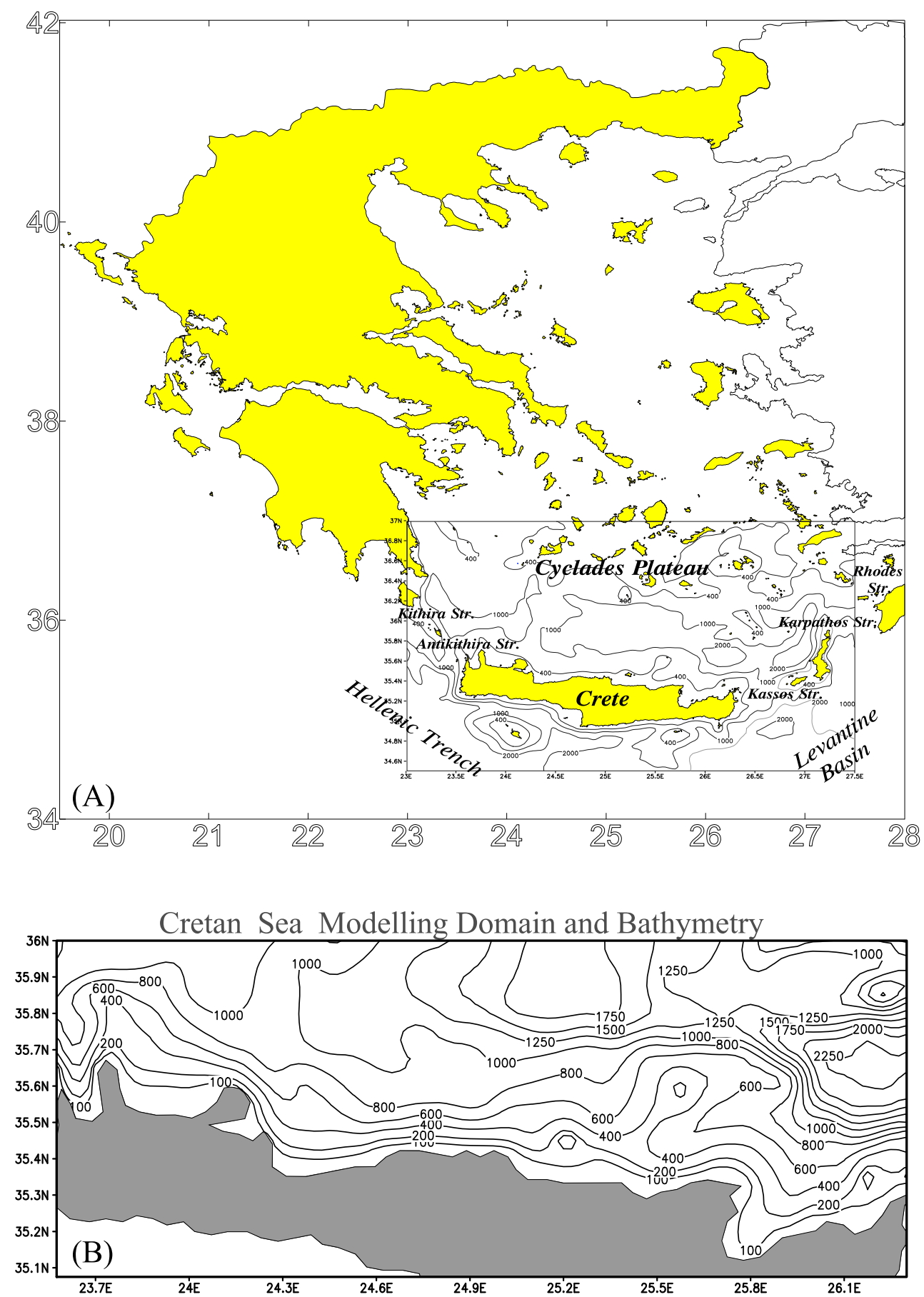

Fig. 1. (a) Map of the wider area of the Cretan Sea. (b) Model domain and bathymetry.

formed in the Levantine and the south Aegean Sea during February and March, under the influence of dry and cold continental air masses (Georgopoulos et al., 1989; Theocharis et al., 1988). Mesoscale processes play an important role in its formation and spreading. It lies mostly under the MAW with a core depth fluctuating from 50 to $600 \mathrm{~m}$. Its signature is salinity maximum found mostly in the subsurface but also in the surface layers, when and as it is being formed. The LIW spreading is very slow and its core salinity in the eastern Ionian and the Cretan Passage reaches approximately 38.9 psu (Theocharis et al., 1999), while its temperature is $14.5^{\circ} \mathrm{C}$ at the sill depths (Theocharis et al., 1993). Transitional Mediterranean Water (TMW) occupies the layers under the LIW at a depth of 700-1600 m. This water mass has occasionally been detected in several regions. In late summer 1987, temperature and salinity distributions in the Cre$\tan$ Sea revealed waters that were relatively colder $\left(14.25^{\circ} \mathrm{C}\right)$ and slightly less saline (38.88-38.90 psu) than the intermedi- 
ate waters. These occupied the deep layers (650-2000 m) of the eastern Cretan basin. Waters with transitional characteristics were also observed at the same depths in other regions of southeast Aegean, including the Eastern Straits through which these waters seem to enter the Aegean. TMW, entering the south Aegean mainly through the Kassos and Antikithira Straits at very low speeds $(\sim 5 \mathrm{~cm} / \mathrm{sec})$ after following two opposite paths, fills the intermediate layers of the basin below the CIW.

Below $800 \mathrm{~m}$ there is a thick layer extending right to the bottom, called the Cretan Deep Water (CDW), with salinity exceeding $39.01 \mathrm{psu}$ and a potential temperature of about $14^{\circ} \mathrm{C}$. This is the only layer that does not seem to be affected by the mesoscale variability of the region and at the same time it is of prime importance in the hydrology of the Eastern Mediterranean Sea (Theocharis et al., 1993). Understanding the complicated hydrological structure and circulation patterns appearing within the Cretan Sea area calls for highresolution numerical modelling efforts. At the same time, a limited area model of the Cretan Sea requires the maximum possible information on the open boundaries, since the general circulation of the central and eastern Levantine area controls a great part of the circulation characteristics of the Cretan Sea.

In this work we present the Cretan Sea shelf-model setup and the modelling effort based on the concept of nested shelf models, within the framework of MFSPP (Mediterranean Forecasting System Pilot Project).

\section{Materials and methods}

\subsection{Model domain and initialisation}

The computational domain for the Cretan Sea model covers the area between $23.575^{\circ} \mathrm{E}$ to $26.3^{\circ} \mathrm{E}$ and $35.075^{\circ} \mathrm{N}$ to $36^{\circ} \mathrm{N}$. It uses a spherical coordinate system consisting of $38 \times 110$ grid points with a horizontal grid resolution of $1.5 \mathrm{~min}$ both in latitude and longitude. In the vertical there are 24 layers of variable thickness with logarithmic distribution near the surface for greater accuracy where velocity gradients are larger.

The model's bathymetry was obtained from the US Navy Digital Bathymetric Data Base - DBDB5 - (with a nominal resolution of $1 / 12^{\circ} \times 1 / 12^{\circ}$ ) by Cressman's (1959) objective analysis technique. A Shapiro (1970) filter of third order was also applied to the interpolated bathymetry, in order to perform the necessary smoothing (elimination of small-scale noise). The model's bathymetry is shown in Fig. $1 b$.

The model's climatological run was initialised with the Mediterranean Ocean DataBase (MODB-MED4) (Brasseur et al., 1996), which consists of seasonal temperature and salinity profiles on a $1 / 4^{\circ} \times 1 / 4^{\circ}$ horizontal grid enriched with in situ measurements collected by the Institute of Marine Biology of Crete. These data were mapped on the model horizontal grid using the same objective analysis technique as before. Additionally, initial velocities were set to zero. A second run, with the Cretan Sea model nested, as explained
Table 1. Acceptable distances for "inside" and "outside" values used in the Reiniger-Ross scheme for interpolating observed level data to standard levels

\begin{tabular}{cccc}
\hline $\begin{array}{c}\text { Standard } \\
\text { Levels }\end{array}$ & $\begin{array}{c}\text { Standard } \\
\text { Depths }\end{array}$ & $\begin{array}{c}\text { Acceptable } \\
\text { distances for } \\
\text { inside values }\end{array}$ & $\begin{array}{c}\text { Acceptable } \\
\text { distances for } \\
\text { outside values }\end{array}$ \\
\hline 1 & 0 & 5 & 200 \\
$2-10$ & $10-200$ & 50 & 200 \\
$11-13$ & $250-400$ & 100 & 200 \\
$14-17$ & $500-800$ & 100 & 400 \\
$18-21$ & $900-1200$ & 200 & 400 \\
$22-25$ & $1300-1750$ & 200 & 1000 \\
$26-33$ & $2000-5500$ & 1000 & 1000 \\
\hline
\end{tabular}

below with the Levantine and Aegean Eddy Resolving Model (ALERMO) (Korres and Lascaratos, 2003, hereafter KL02), was initialised directly from ALERMO's temperature, salinity, velocity 3-D and free surface elevation 2-D fields obtained during the third year of its climatological run. These data were objectively analysed so that they could be mapped onto Cretan Sea model domain.

\subsection{Data analysis}

In order to examine the ability of the model to reproduce the main general circulation features, taking into account the nesting techniques, a series of simulation experiments took place. Table 2 depicts the two main simulation experiments presented here. For the needs of initialisation and forcing of the model data from the Mediterranean Oceanographic DataBase (MODB) and 10-day averages resulting from ALERMO model were analysed.

The primary source for the historical temperature and salinity data sets used in the first experiment was the MODB (raw data covering the period 1900 to 1995). A substantial amount of additional historical data was used from in situ measurements collected by the Institute of Marine Biology of Crete (IMBC). An analysis of these data, as well as the vital step of quality control of the physical parameters took place, in order to create an improved database required for the implementation of the model. These data were seasonally analysed at standard oceanographic analysis levels between the surface and sea bottom. Due to the scarcity of data the examination of the annual cycle was done by composing all data regardless of the year of observation. MODB data include measurements from CTDs and the related STDs, hydrographic casts (station data) with various bottles, and bathythermographs of the mechanical (MBT) and expendable (XBT) varieties. In addition, the collection of CTD profiles of the area of Heraklion (IMBC measurements) was included. Figure 2 depicts profiles with spatial distribution of raw data and the number of observed data points. 
Table 2. The two main simulation-experiments

\begin{tabular}{|c|c|c|c|}
\hline $\begin{array}{l}\text { Experi- } \\
\text { ment }\end{array}$ & $\begin{array}{l}\text { Initial } \\
\text { conditions }\end{array}$ & Heat fluxes & Boundary conditions \\
\hline SI-MO & $\begin{array}{l}\text { T, S: seasonal, } \\
\text { MODB }\end{array}$ & $\begin{array}{l}\text { Monthly } \\
\text { Budyko-Bignami } \\
\text { data set }\end{array}$ & $\begin{array}{l}\text { T, S: Upstream advection. On inflow } \\
\text { T,S prescribed by MODB } \\
\text { Baroclinic velocities: } \\
\text { Sommerfeld radiation } \\
\text { Barotropic velocities: } \\
\text { Flather boundary condition with } \\
\text { zero prescribed barotropic velocity } \\
\text { and free surface elevation } \\
\text { Free surface elevation: Zero-gradient }\end{array}$ \\
\hline SI-AL & $\begin{array}{l}\text { T, S: 10-day } \\
\text { ALERMO } \\
\text { averages }\end{array}$ & $\begin{array}{l}\text { Evaporation by } \\
\text { Kondo-Bignami, } \\
\text { Total heat flux } \\
\text { from ALERMO } \\
\text { data set }\end{array}$ & $\begin{array}{l}\text { T, S: Upstream advection. On inflow } \\
\text { T, S prescribed by ALERMO } \\
\text { Baroclinic velocities: } \\
\text { prescribed by ALERMO } \\
\text { Barotropic velocities: } \\
\text { Flather boundary condition with } \\
\text { barotropic velocity and free surface } \\
\text { elevation prescribed by ALERMO } \\
\text { Free surface elevation: Zero-gradient }\end{array}$ \\
\hline
\end{tabular}

In the water column down to a depth of 2000 m, 25 "standard levels" were used, including the surface level $(0 \mathrm{~m})$. These levels represent the following depths: $0,5,10,15$, 20, 25, 30, 35, 40, 50, 80, 100, 120, 160, 200, 240, 280, 340, $420,500,620,850,1250,1750$, and $2000 \mathrm{~m}$. Observed data that did not occur exactly at a standard level were interpolated to standard level data. Any method used to make vertical interpolation from observed readings to standard level values must be as accurate as possible without creating spurious features; the method chosen is a modified Reiniger-Ross scheme (Reiniger and Ross, 1968) using four observed values surrounding the standard level in question, the two closest shallower values and the two closest deeper values. The closest shallower and deep values are referred to as "inside" values, and the two farthest shallow and deep values are referred to as "outside" values. All must be within the depth difference criteria shown in Table 1. The modifications to the Reiniger-Ross method are as follows: The first accepted value was used directly as the surface value. Here subjective quality control was performed to exclude all extremes. Then, for the Reiniget-Ross interpolated values that did not fall between the two nearest observed readings (observed values directly above and below it) a linear interpolation was substituted. If four points were not available to perform the Reiniger-Ross interpolation, such as at the beginning or end of a profile, then a three-point Lagrangian interpolation was performed, and where this was not possible, a linear interpolation was used. This occurred mainly when, as noted above, the outer max depth criteria were violated, or when an additional check was violated, or finally, when there were only two surrounding values in a profile. For observed values taken directly at a standard depth, direct substitution was used.

Due to the lack of data in some areas, certain empirical criteria were applied, and as a part of the last processing step, subjective judgment was used. Any parameter values flagged as spurious in an observed level check were excluded from the calculation of standard level values. The total number of observations that fall into the desired area and used in the study were 217 CTD observations (29 from MODB and 188 from IMBC), 73 MODB BTL observations, and 978 MODB BT observations. Finally, density checks, where possible, and subjective quality control were performed. All available (quality controlled) observations were averaged in each box for each month (for the surface data) and for each season during the 95-year period. Bias corrections, if applicable, were made to each individual observation before averaging. Due to the uneven distribution of these quality-controlled data, in the modelling domain, and in order to fill the missing gaps, data were treated as station data and were objectively mapped onto the model's grid using the Cressman (1959) technique. For consistency it was decided to use the same objective analysis technique for all data needed for the Cretan Sea model run, although comparison with bi-linear interpolation method was used in one of the experiments giving similar results.

For the next experiments, the 10-day averaged 3-D fields 

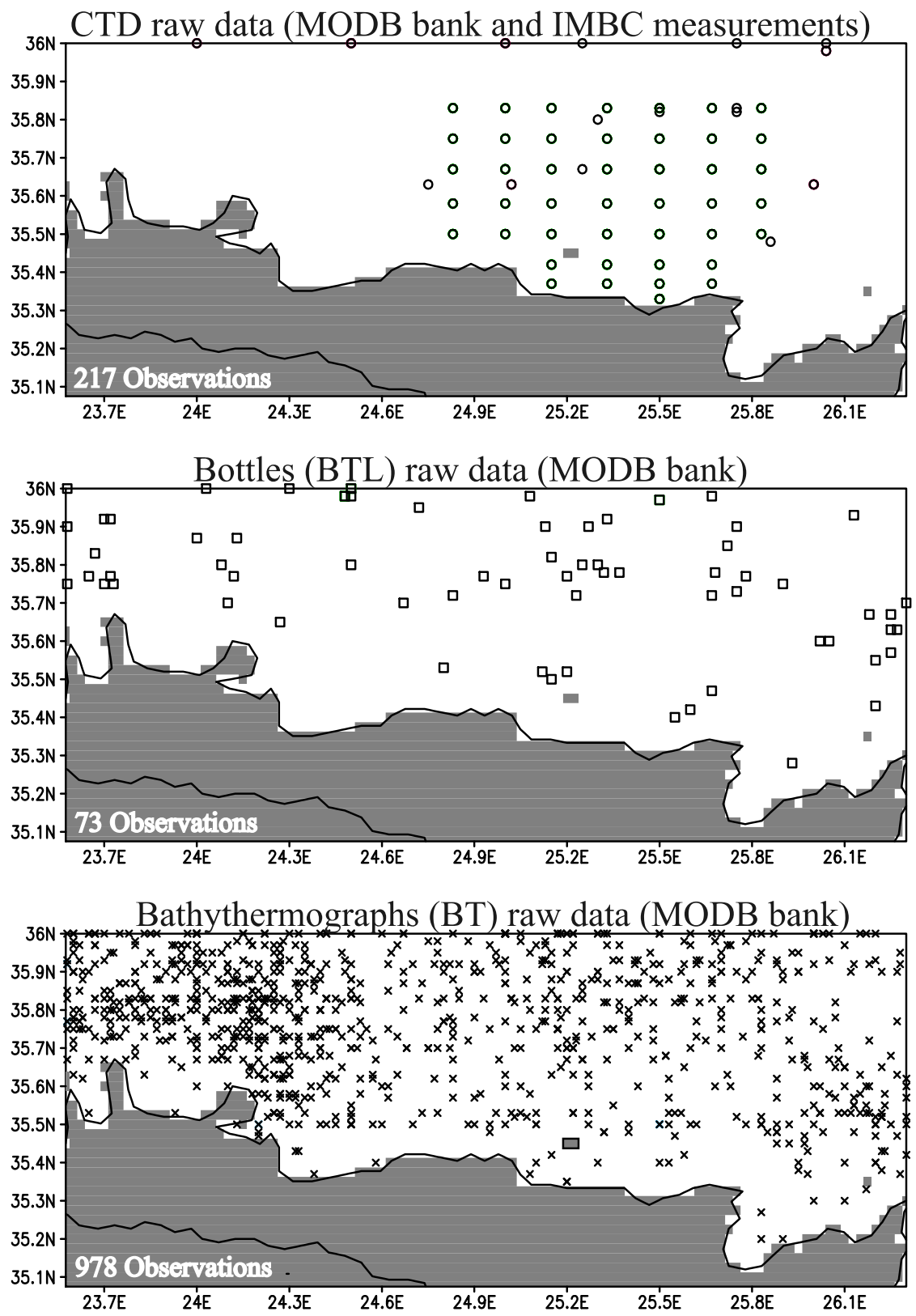

Fig. 2. Spatial distribution of (a) CTDs, (b) Bottles, and (c) Bathythermographs in the modelling domain.

of temperature, salinity, and velocity, resulting from the third year of ALERMO's climatological run, were objectively analysed over the Cretan Sea model grid (and if necessary, were smoothed by a first-order Shapiro filter to eliminate small-scale noise), in order to provide lateral and surface (temperature and salinity) boundary conditions. Objective analysis was also performed for the March temperature and salinity profiles for the needs of model initialization, as well as for the atmospheric data that were necessary to drive the climatological runs of the Cretan Sea model. The atmospheric data set, described in KL02, consists of monthly fields of wind stress components, net heat flux, net shortwave radiation and evaporative heat flux fields. These data were computed by KL02 using 1979-1993 ECMWF reanalysis 6-hour atmospheric parameters of wind velocity, air temperature, relative humidity and optimally tuned bulk formulae. Cloud-cover data necessary for heat flux computations were taken from COADS 1979-1993 monthly data set, while monthly SST fields for the same period came from Reynolds.

\subsection{Model description}

The Cretan Sea model is an implementation of the 3-D Princeton Ocean hydrodynamic Model (POM) (Blumberg and Mellor, 1987). POM is a primitive equation, time dependent, $\sigma$-coordinate, free surface, and split mode (external - internal) time step model. It calculates the following equa- 
tions for the velocity $U_{i}=(U, V, W)$, temperature $T$, and salinity $S$.

$$
\frac{\vartheta U_{i}}{\partial x_{i}}=0
$$

$$
\begin{gathered}
\frac{\vartheta(U, V)}{\vartheta t}+U_{i} \frac{\partial}{\partial x_{i}}(U, V)+f(-V, U)=\left(-\frac{1}{\rho_{0}}\right) \\
{\left[\frac{\partial p}{\partial x}, \frac{\partial p}{\partial y}\right]+\frac{\partial}{\partial z}\left[K_{M} \frac{\partial}{\partial z}(U, V)\right]+\left(F_{U}, F_{V}\right)}
\end{gathered}
$$$$
\frac{\vartheta T}{\vartheta t}+U_{i} \frac{\vartheta T}{\vartheta x_{i}}=\frac{\partial}{\partial z}\left[K_{H} \frac{\partial T}{\partial z}\right]+F_{T}+\frac{\partial R}{\partial z}
$$

$$
\frac{\vartheta S}{\vartheta t}+U_{i} \frac{\vartheta S}{\vartheta x_{i}}=\frac{\partial}{\partial z}\left[K_{H} \frac{\partial S}{\partial z}\right]+F_{S}
$$

An embedded second moment turbulence closure submodel (Mellor and Yamada, 1982) is contained that gives the vertical eddy viscosity and diffusivity parameters $K_{M}$ and $K_{H}$. The analogous horizontal parameters $F_{U}, F_{V}, F_{T}$, and $F_{S}$ are calculated through the Smagorinsky (1963) formulation. The density $\rho=\rho(T, S, P)$ is calculated from the UNESCO equation of state adapted by Mellor (1991). The solar radiation flux $Q_{s}$ is directly added to the heat Eq. (3) through the term $\partial R / \partial Z$, where

$R(z)=Q_{s}\left[\operatorname{Tr} e^{\lambda_{1} z}+(1-\operatorname{Tr}) e^{\lambda_{2} z}\right]$.

The transmission coefficient $T r$ in Eq. (5) is set equal to 0.77 , while the attenuation coefficients are $\lambda_{1}=0.666 \mathrm{~m}^{-1}$ and $\lambda_{2}=0.0714 \mathrm{~m}^{-1}$, corresponding to Jerlov's (1976) water type II classification. The double exponential distribution is derived from Paulson and Simpson (1977) and parameterises in an optimal way the selective absorption of the short and longer wavelengths in the vertical. The first exponential term in Eq. (5) represents the rapid attenuation of the solar radiation in the upper $5 \mathrm{~m}$ due to the absorption of the longer wavelengths, while the second exponential accounts for the attenuation of short wavelengths below $10 \mathrm{~m}$.

\subsection{The simulation experiments}

\subsubsection{The first experiment setup}

The first simulation experiment (SI-MO - Table 2) was integrated for a 3-year period using monthly climatological heat flux and wind stress fields, as derived from the ECMWF 1979-1993 6-hour reanalysis atmospheric parameters data. For the derivation of net long-wave radiation at the sea surface the Bignami formula (Bignami et al., 1995) was used while evaporative and sensible heat flux fields were derived from Budyko formula (Budyko, 1963). The net short-wave radiation at the sea surface was computed using Reed's formula (Reed, 1977) and COADS monthly cloud cover data for the period 1979-1993.
For the first simulation experiment (SI-MO) open boundary conditions are used along the west, north, and east boundaries. Upstream advection Eq. (6) is used for the temperature $T$ and salinity $S$, and where there is an inflow, $T$ and $S$ are specified directly by the MODB monthly climatology (properly interpolated in time).

$\frac{\vartheta T}{\vartheta t}+U \frac{\partial T}{\partial x}=0$

The normal barotropic velocities at the model boundaries are described by the Flather (1976) boundary condition (7), assuming that the prescribed values $\bar{U}_{0}$ and $\varsigma_{0}$ are zero at the boundary:

$\bar{U}=\bar{U}_{0}+\varepsilon \sqrt{\frac{g}{H}\left(\varsigma_{0}-\varsigma\right)}$.

In Eq. (7) $\varepsilon= \pm 1$, depending on the position of the open boundary $(-1$ for an eastern or northern boundary, and +1 for a western or southern boundary). The tangential barotropic velocities at the open boundaries of the model are set equal to zero. For the baroclinic velocities (internal mode) at the open boundaries a Sommerfeld's onedimensional radiation condition was applied using an internal wave phase speed $c_{i}=\sqrt{g H \times 10^{-3}}$ ( $H$ is the local water depth). Finally, a zero-gradient condition was used for the free surface elevation.

\subsubsection{Nesting with the intermediate model (ALERMO)}

The Cretan Sea model (fine grid model) is one-way nested with the ALERMO model (coarse grid model) through a finite difference simple technique, which guarantees volume conservation between the two models and efficient radiation of unwanted disturbances out of the modelling area. Oneway nesting means that the boundary conditions of the fine grid model are prescribed by the prognostic variables extracted from the coarse resolution model, while the solution of the latter is not modified by the solution of the fine grid model in their common overlapping area.

The ALERMO model is an implementation of the POM model within the eastern Mediterranean region (east of $20^{\circ} \mathrm{E}$ ), with a $1 / 20^{\circ} \times 1 / 20^{\circ}$ horizontal resolution and 31 levels in the vertical. It was integrated for a 3-year period using the climatological wind stress fields as derived from the ECMWF 1979-1993 reanalysis data and the heat flux fields which were derived diagnostically from an 8-year integration of the global Mediterranean general circulation model OGCM (the Modular Ocean Model implemented within the Mediterranean region with a $1 / 8^{\circ} \times 1 / 8^{\circ}$ horizontal resolution and 31 levels in the vertical; Pinardi and Masetti, 2000) and forced with the same monthly climatology of wind stress and the Kondo-Bignami heat fluxes data set. During the last year of the ALERMO model integration, all prognostic variables of the model (free surface elevation, barotropic and baroclinic velocity fields, temperature and salinity) are stored in the form of 10-day averages for further 
use.

\section{Lateral boundary conditions}

The nesting with the ALERMO model is applied along the three open boundaries (west, east and north) of the Cretan Sea model. The ALERMO 10-day average prognostic variables are interpolated onto the $x-z$ and $y-z$ open boundary section of the Cretan Sea model at each time step of the model integration. Spatial interpolation is done using the Cressman objective analysis technique, while the interpolation in time is linear. The constraint of volume conservation between the two models is applied as follows. Assume that $\boldsymbol{U}_{C}^{I N T}$ is the interpolated ALERMO velocity onto the Cretan Sea model open boundary section and $\hat{n}$ is the unit vector normal to the boundary section. Then, the interpolated velocity field $\boldsymbol{U}_{C}^{I N T} \cdot \hat{n}$ is corrected in such a way that:

$\int_{l_{1}}^{l_{2}} \int_{-H_{F}(l)}^{\varsigma_{F}^{(l)}} \boldsymbol{U}_{C}^{I N T} \cdot \hat{n} d z d l=\int_{l_{1}}^{l_{2}} \int_{-H_{C}(l)}^{\varsigma_{C}(l)} \boldsymbol{U}_{C} \cdot \hat{n} d z d l$,

where $l_{1}, l_{2}$ are the extremes of the open boundary section, while $H_{C}, \varsigma_{C}$ and $H_{F}, \varsigma_{F}$ stand for ALERMO and Cretan Sea model bathymetries and free surface elevation at the open boundary under consideration.

The boundary condition for the normal barotropic velocity at the open boundary is a modified Flather (1976) condition, which efficiently allows interior disturbances - due to possible mismatches between coarse and nested values to pass out through the lateral boundary. Flather's condition has already been tested by Palma and Matano (2000) in a 3-D POM model setup resulting in a reasonably good performance. This specific boundary condition assumes a Sommerfeld-type radiation condition with a one-dimensional version of the continuity equation to yield an equation for the normal barotropic velocity at the open boundary. Assuming that $\bar{U}_{F}, \varsigma_{F}$ are the normal to the boundary section barotropic velocity component and the free surface elevation of the Cretan Sea model at its open boundary section, then the boundary condition can be written as:

$\bar{U}_{F}=\bar{U}_{C}^{I N T} \pm \frac{\sqrt{g H_{F}}}{H_{F}+\varsigma_{F}}\left(\varsigma_{C}^{I N T}-\varsigma_{F}\right)$,

where $\bar{U}_{C}^{I N T}=\frac{1}{H_{F}+\varsigma_{F}} \int_{-H_{F}}^{\varsigma_{C}} U_{C}^{I N T} d z$ and $\varsigma_{C}^{I N T}$ is the ALERMO free surface elevation interpolated along the lateral boundary section area. The upper sign (+) in Eq. (9) is for the western or the southern boundary, while the lower sign (-) applies to the eastern or the northern boundary of the model. The tangential barotropic velocity, say $\bar{V}_{F}$, at the open boundary is directly prescribed from ALERMO:

$\bar{V}_{F}=\bar{V}_{C}^{I N T}$
The internal mode velocities (normal and tangential) at the open boundary are also directly prescribed from the ALERMO model:

$U_{F}=U_{C}^{I N T}, V_{F}=V_{F}^{I N T}$.

To update the temperature and salinity values at the open boundaries, an upstream advection scheme is used whenever the normal velocity is directed outwards from the Cretan Sea modelling area:

$\frac{\partial T_{F}}{\partial t}+U_{F} \frac{\partial T_{F}}{\partial n}=0, \frac{\partial S_{F}}{\partial t}+U_{F} \frac{\partial S_{F}}{\partial n}=0$.

In cases of inflow through the open boundary, temperature and salinity are prescribed directly from the interpolated ALERMO temperature and salinity profiles:

$T_{F}=T_{C}^{I N T}, S_{F}=S_{C}^{I N T}$.

Finally, for the free surface elevation at the open boundary a zero-gradient condition is adopted:

$\frac{\partial n_{F}}{\partial n}=0$.

\section{Forcing data}

\section{i. Momentum:}

The momentum budget at the surface takes the form:

$\left.\rho_{0} K_{m} \frac{\partial \boldsymbol{u}_{h}}{\partial z}\right|_{z=0}=\boldsymbol{\tau}$

where $\tau$ is the wind stress provided by ECMWF perpetual year monthly climatology, as described in KL02.

\section{ii. Heat budget:}

The heat budget boundary condition at the surface is:

$\left.\rho_{0} c_{p} K_{H} \frac{\partial T}{\partial z}\right|_{z=0}=Q_{r}-Q_{s}+c_{a}\left(T_{A L E R M O}-T\right)$,

where $Q_{T}$ is the total heat flux field diagnosed from the third year of the ALERMO climatological run (using an analogous boundary condition) and mapped onto the Cretan Sea model grid. The solar heat flux term $Q_{S}$ is directly inserted into the temperature Eq. (3), as already discussed, and thus, it is subtracted from the total heat flux term in the surface heat budget boundary condition specification. Monthly climatological fields of $Q_{S}$ have been calculated by KL02 using the Reed formula (Reed, 1977) and monthly cloud coverage values from the COADS data set spanning the period 19791993. The term $c_{a}\left(T_{\mathrm{ALERMO}}-T\right)$ where $c_{a}$ is set to $10 \mathrm{~W}$ $m^{-2} C^{-1}$ and $T_{\text {ALERMO }}$ is the ALERMO model SST, acts as a weak adjustment to the ALERMO total heat flux field.

The OGCM perpetual integration experiment upon which the ALERMO model is based was forced with the KondoBignami heat flux data set, plus an additional heat flux 

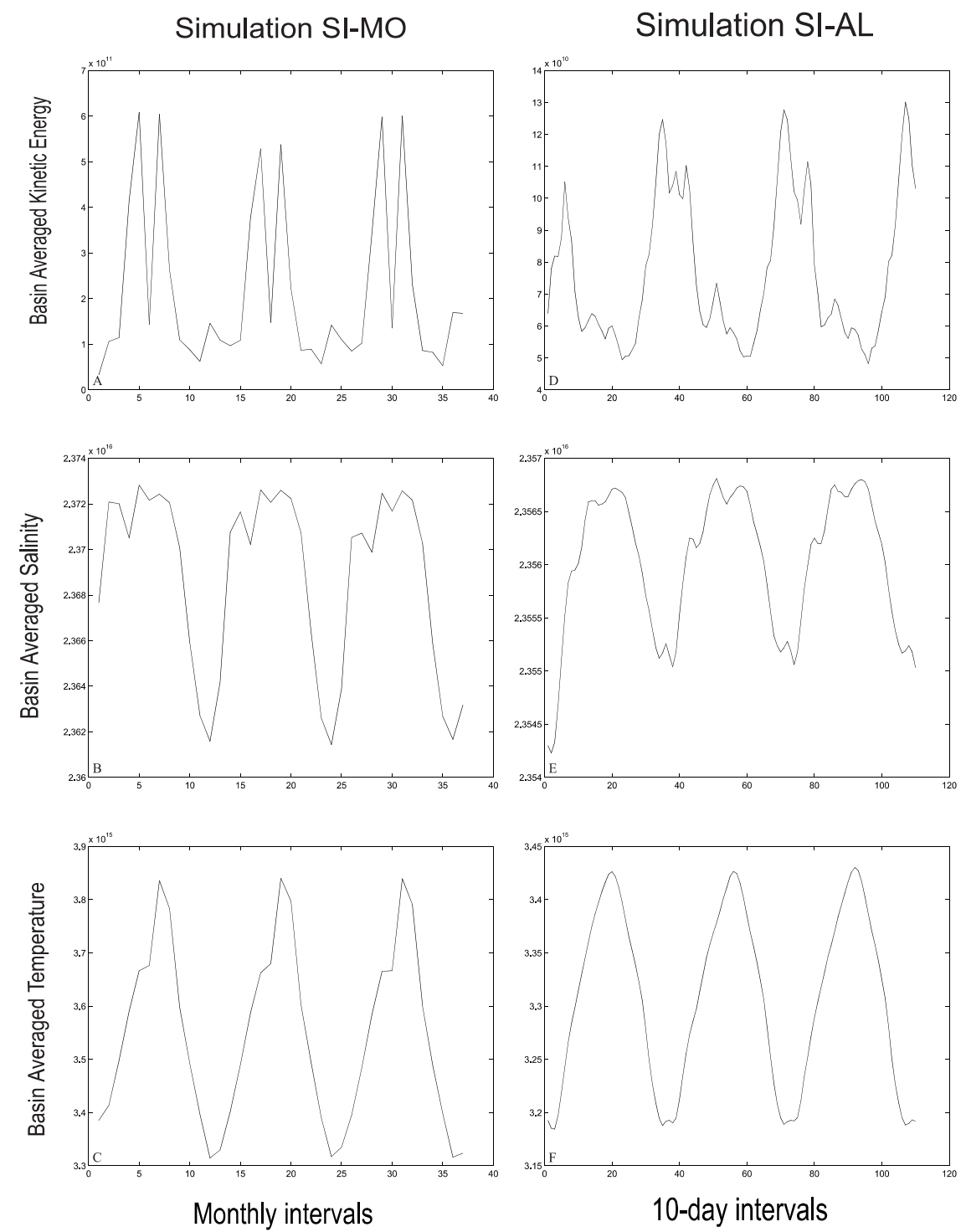

Fig. 3. Simulation SI-MO: (a) Basin averaged kinetic energy time series, (b) Basin averaged salinity time series, and (c) Basin averaged temperature time series. Simulation SI-AL: (d) Basin averaged kinetic energy time series, (e) Basin averaged salinity time series, and (f) Basin averaged temperature time series.

correction term $c_{o}\left(T^{*}-T_{O G C M}\right)$, where $c_{o}=25 \mathrm{~W} \mathrm{~m}^{-2} \mathrm{C}^{-1}$ and $T^{*}$ is a monthly SST observational climatology. The Kondo-Bignami data set, as discussed in KL02, corresponds to a strongly positive $\left(+17.3 \mathrm{~W} \mathrm{~m}^{-2}\right)$ annual heat budget for the whole Mediterranean region. This data set is then adjusted twice, first in the course of the OGCM climatological integration and second in the course of the ALERMO integration within the eastern Mediterranean area.

\section{iii. Salinity budget:}

The salinity boundary condition at the surface is as follows:

$\left.K_{H} \frac{\partial S}{\partial z}\right|_{z=0}=S(E-P)+c_{2}\left(S_{A L E R M O}-S\right)$ where $S$ and $S_{\text {ALERMO }}$ represent the Cretan Sea and ALERMO model sea surface salinity respectively. The evaporation rate $E$ was calculated from the latent heat flux $Q_{e}$, as provided by the Kondo-Bignami climatological data set described in KL02:

$E=\frac{Q_{e}}{\rho L_{v}}$

In the above expression $L_{v}$ is taken to be equal to $2.5008 \times$ $10^{6} \mathrm{Jkg}^{-1}$, and $\rho=1023 \mathrm{kgm}^{-3}$ is the density of seawater. The precipitation rate $P$ is obtained from Jaeger's (1976) monthly precipitation climatology, initially mapped on a $5^{\circ} \times 2.5^{\circ}$ grid. The appearance of the correction term $c_{2}\left(S_{A L E R M O}-S\right)$ in Eq. (17) accounts for the imperfect knowledge of $E-P$ (especially of $P$ ). In this term $c_{2}$ has been set (upon sensitivity studies) equal to $0.7 \mathrm{~m} /$ day. 

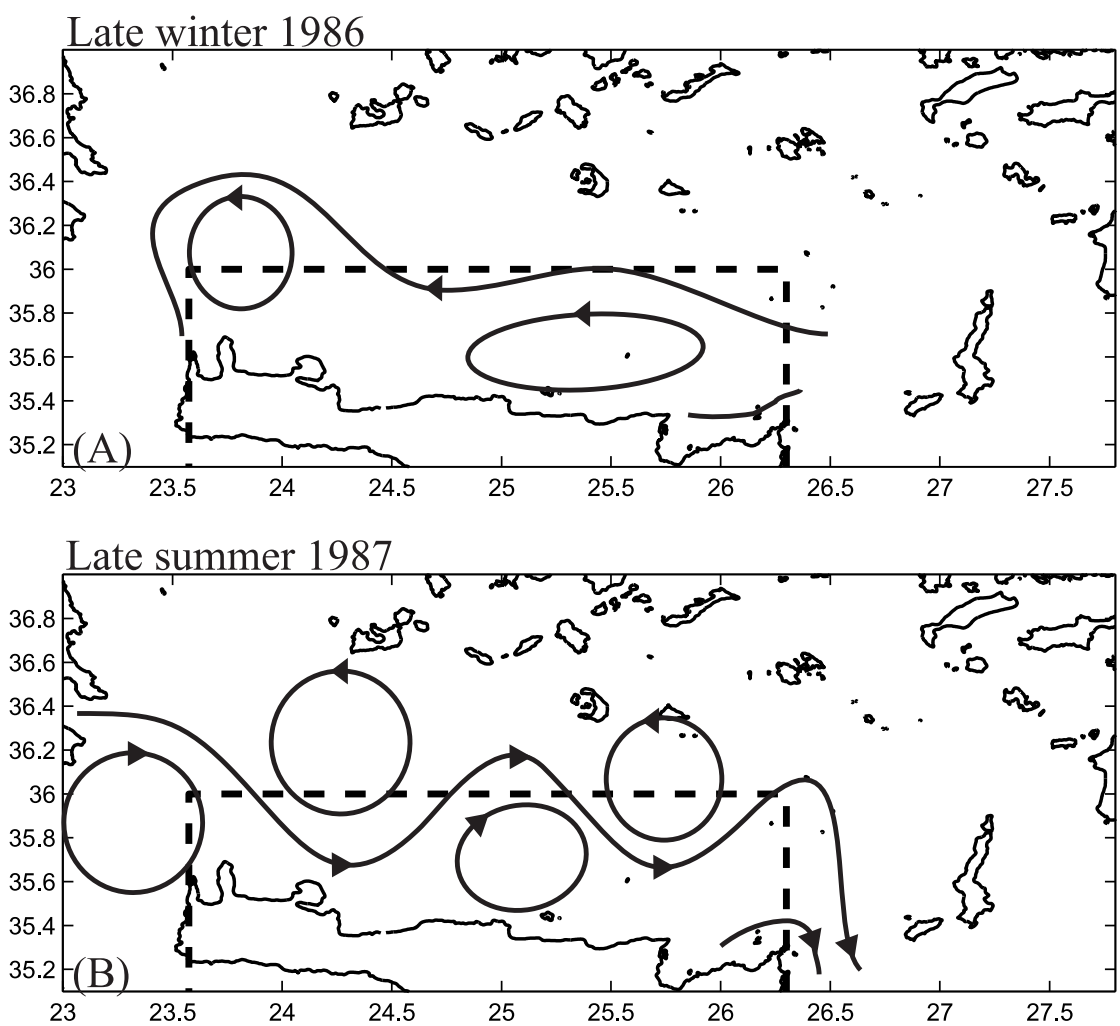

Fig. 4. Schematic configurations of the main circulation features for (a) late winter 1986, and (b) late summer 1987. (After Theocharis et al., 1993).

\section{Results}

The Cretan Sea main experiments are listed in Table 2. After the first year of the simulations both circulation and thermohaline water structure reach a quasi-steady state, as is shown in Fig. 3, with the basin average kinetic energy of the systems reaching a repetitive pattern, reflecting a quite fast response to the applied forcings.

\section{Observations}

The observational evidence about the circulation characteristics of the Cretan Sea is rather limited due to the spatial/temporal scarcity of the data collected within this particular area. In addition, the important interannual variability characterizing the whole eastern Mediterranean general circulation (Pinardi et al., 1997) further obscures the climatological characteristics of the Cretan Sea. The analysis of the data collected during March-April 1986 (POEM-II-86) and September-October 1987 (POEM-V-87) revealed an intense meso-scale flow field within the Cretan Sea, coupled with the general circulation and sub-basin scale features of the Levantine basin. A strong seasonal cycle was observed involving flow reversals from the winter to summer period. During the winter of 1986, for example, the intense Asia Minor Current (AMC), which flows along the northwest border of the Rhodes gyre, branches to the north and enters the Aegean through the eastern straits of the Cretan arc (Theocharis et al., 1993). The most intense inflow was observed through the Kassos strait. This branch bifurcated again in the eastern part of the Cretan Sea, forming a westward and a northward flow. The westward flowing branch meandered inside the Cretan Sea along a large, multi-centered cyclonic flow region, reaching the western straits of the Aegean Sea. During the summer of 1987, on the other hand, an eastward current meandered north of Crete, interconnecting a series of cyclonic and anticyclonic eddies (Theocharis et al., 1993). Waters coming out of the Aegean through the Kassos and Karpathos Straits and some inflow from the Levantine basin to the Aegean Sea along the Rhodes Straits are observed.

\section{The MODB-based experiments}

For the first experiment (SI-MO), the MODB data are used and the results of the third perpetual year are presented. The model results show circulation features similar to those described by Theocharis et al. (1993) (Fig. 4). Velocity fields and streamlines for the months of February and August at the subsurface $(30 \mathrm{~m})$ and mid-depth $(280 \mathrm{~m})$ are shown in Fig. 5. The Cretan Sea seems to be dominated by a succession of cyclonic and anticyclonic eddies. A cyclonic circulation pattern and a westward flow are the main characteristics of the winter and late winter, while a meandering eastward current is the prevailing characteristic of the summer and late summer. These main structures are also persistent in the mid-depths. According to Theocharis et al. (1993), this flow reversal 

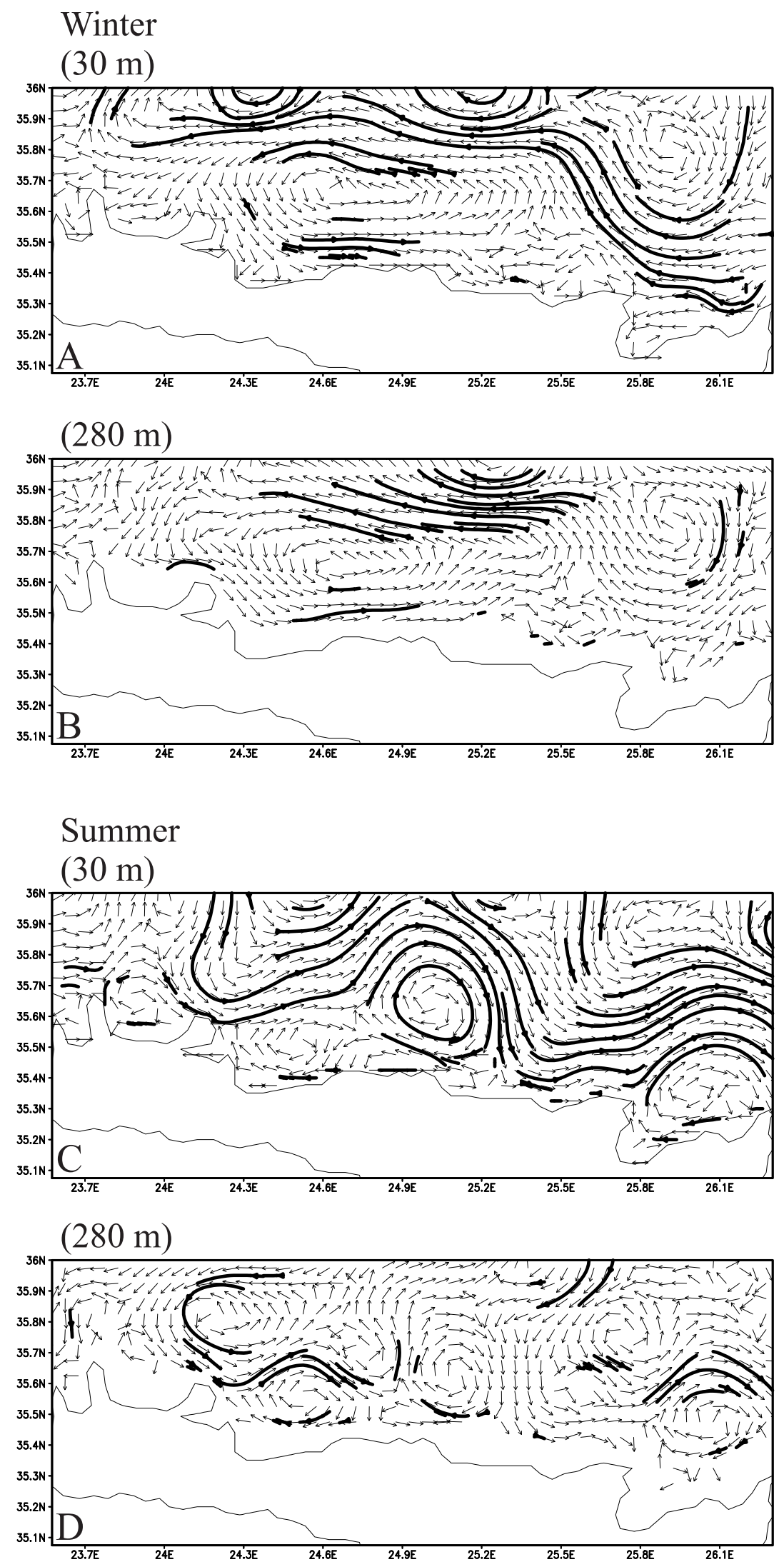

Fig. 5. Circulation patterns in the modelling area of the Cretan Sea corresponding to the third perpetual year simulation SI-MO. (a) Winter (February) sub-surface $(30 \mathrm{~m})$, (b) Winter (February) mid-depth $(280 \mathrm{~m})$, (c) Summer (August) sub-surface (30 m), (d) Summer (August) mid-depth $(280 \mathrm{~m})$. 
SEPTEMBER: CRETAN MODB 3rd perp.year data
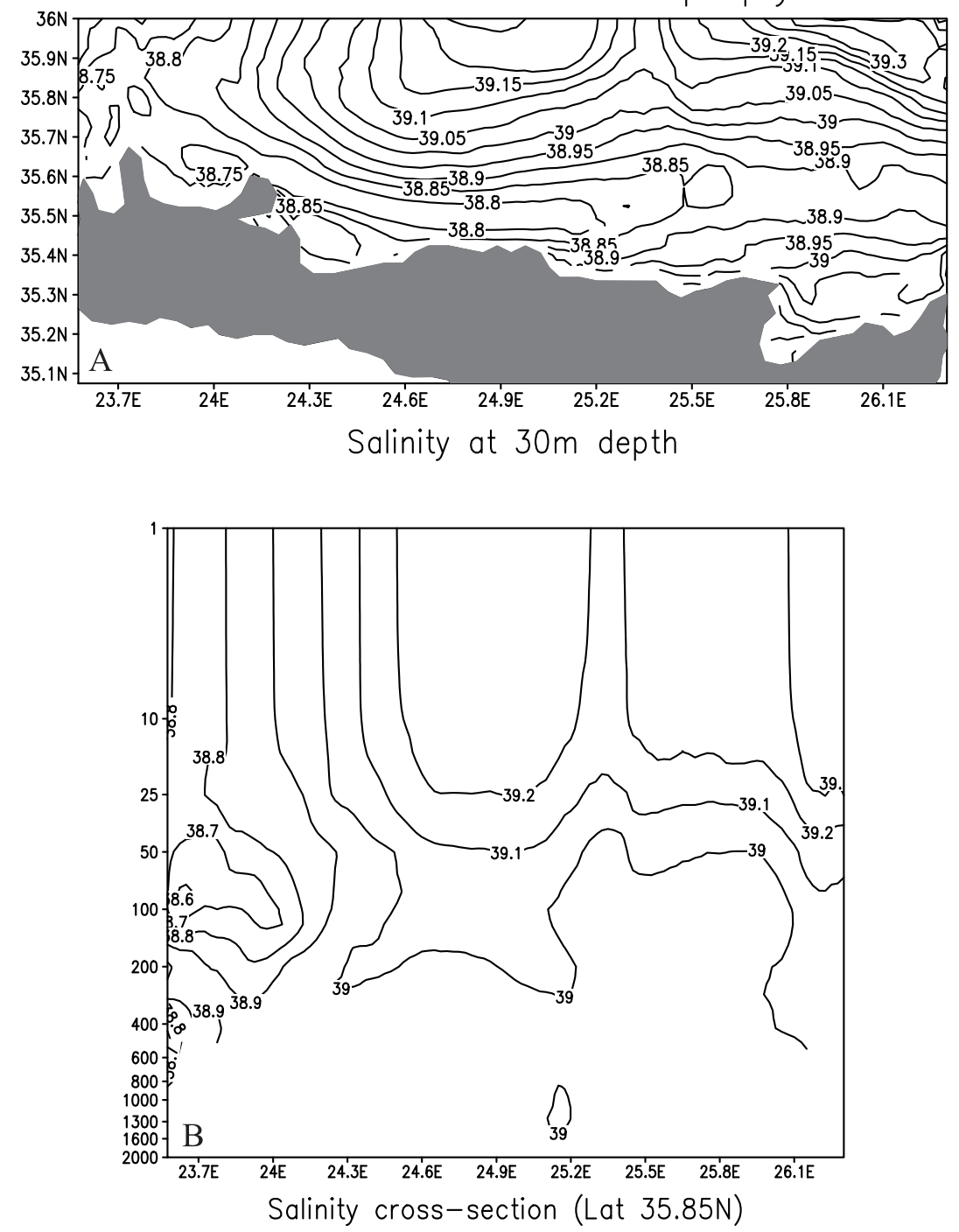

Fig. 6. Salinity profiles of the third perpetual year of SI-MO during late summer, (a) at the sub-surface $(30 \mathrm{~m})$, and (b) cross section at latitude $35.85 \mathrm{~N}$. between winter and summer is the most important feature of the Cretan Sea. During winter an expanded central cyclone is identified south, close to Crete's shore, as a generic response pattern to the westward current (Figs. 5a, b), exhibiting seasonal variability in terms of its intensity, form, and position, occasionally forming a two-lobe structure, and remaining the major feature of the season, while other smaller anticyclonic eddies to the north of the current contribute to the complexity of the circulation pattern. During this period currents are weaker than those in summer, when the flow reversal is the most prominent and intense characteristic. In early summer it manifests itself as a strong eastward current following a meandering pathway with an eastward direction and contributing to the development of three anticyclones to the south of the flow and two cyclonic eddies to its north (Figs. 5c,d).

In the Ionian Sea, MAW can be detected by its subsurface salinity minimum throughout the year (Manzella et al., 1988). As it enters the Cretan Sea through the Cretan Arc
Straits, surface water of higher temperature and salinity covers MAW, its salinity increases (38.7-8.9 psu) and can be detected in several regions as a subsurface $(30-200 \mathrm{~m})$ salinity minimum (Theocharis et al., 1993). During late summer, following the eastward current, it spreads along the northern coasts of Crete (Fig. 6a). Along its route, it becomes saltier as it mixes with more saline waters. Figure $6 \mathrm{~b}$ shows a cross section at latitude $35.85 \mathrm{~N}$ during the same period (September), where major water masses (MAW, CSW, LIW) are detected.

\section{The ALERMO-based experiments}

Next, the flow field of the Cretan Sea, as it emerges from the climatological model, run nested, as described in Sect. 2.4.2 (SI-AL), is presented. In Fig. 7a the late winter (March) sub-surface $(30 \mathrm{~m})$ circulation pattern of the southern Aegean Sea, corresponding to the climatological model run of the 
a) 11-20 MARCH (30 m)

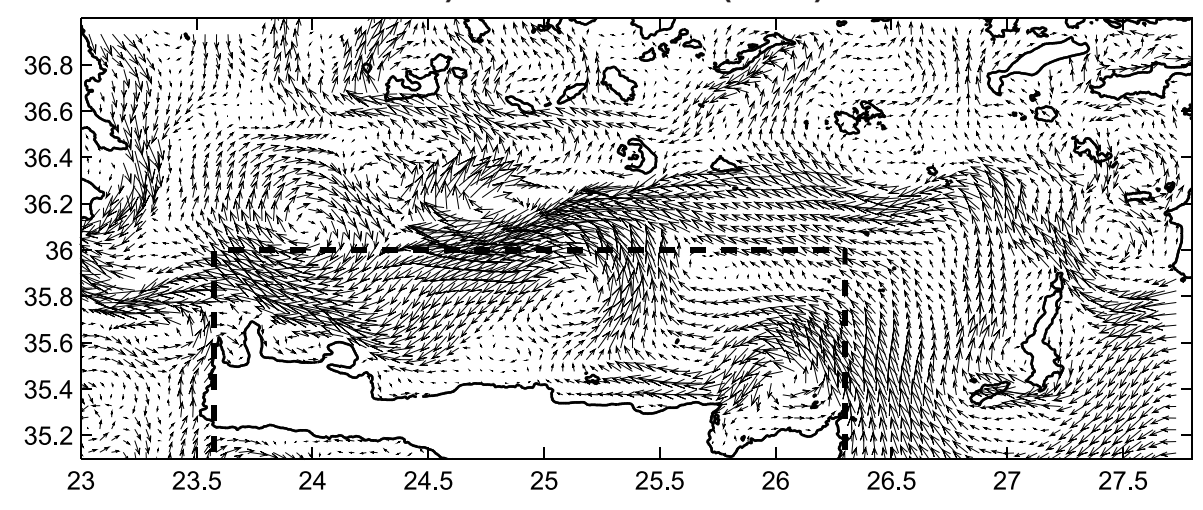

b) 11-20 SEPTEMBER $(30 \mathrm{~m})$

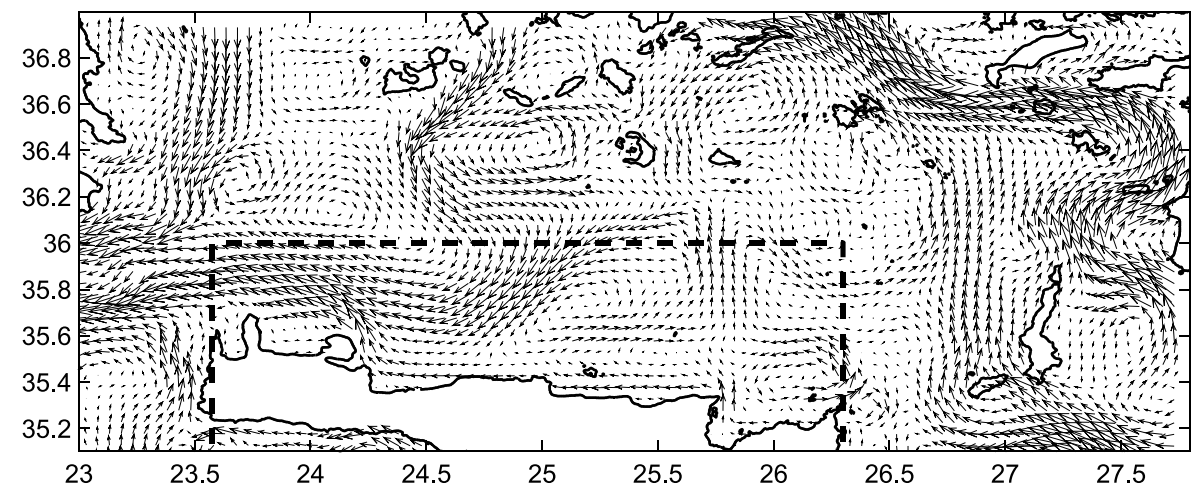

Fig. 7. (a) Winter (11-20 March) subsurface (30 m) circulation pattern for the southern Aegean, corresponding to ALERMO's climatological run (third year). Dashed line denotes Cretan Sea model domain. (b) Same as (a) but for summer (11-20 September)

ALERMO model, is presented. An intense AMC is observed along the northern border of the Rhodes gyre, which then enters the southern Aegean Sea through the eastern Cretan Arc Straits. The AMC branches entering the southern Aegean Sea through the Kassos and Rhodes-Karpathos Straits merge into a unique westward current just after their entrance, which flows at approximately $36^{\circ} \mathrm{N}$. An intense current enters the Aegean Sea along the eastern coast of Crete and immediately meanders to form a cyclonic eddy located to the northeast of Crete. At $25.2^{\circ} \mathrm{E}$ the current turns to the north to merge with the westward flow at $36^{\circ} \mathrm{N}$. The whole system moves south-westwards and finally exits through the KithiraAntikithira straits. In conclusion, during this season, the Cretan Sea circulation characteristics are controlled largely by the Levantine origin waters flowing into the Aegean Sea through the eastern Cretan Arc Straits. Also, the dipole structure observed (the anticyclone located at $24^{\circ} \mathrm{E}-36^{\circ} \mathrm{N}$ and the cyclone located at $25.2^{\circ} \mathrm{E}-35.8^{\circ} \mathrm{N}$ ) is clearly connected with the meanderings of the intense westward flow to the north of Crete.

The relevant flow pattern corresponding to the Cretan Sea model is shown in Fig. 8a. A rich mesoscale field interconnected with currents and current filaments shows up within the eastern part of the modelling domain. The intense west- ward current entering the Cretan Sea midway at the eastern boundary is directly specified at the open boundary conditions. The same holds for the cyclonic eddy occurring to the south, which is also exhibited by the ALERMO model in this area. The division of the westward flowing current into two branches is also observed in the ALERMO model results, but here it is captured in more detail. The northward branch merges at the northern boundary with an incoming flow, as shown in Fig. 7a. Subsequently, it is provided as a boundary condition from the lower resolution grid to the fine grid as an incoming flow at the northern boundary, merged with the broad current that continues to flow to the southwest and finally exits through the western boundary of the domain. The anticyclonic curvature of the flow observed at the northwest corner of the domain corresponds to the lower part of the anticyclone existent in the ALERMO model flow field and located further north.

The sub-surface circulation pattern during late summer (September), corresponding to ALERMO's run and shown in Fig. 7b, exhibits significant changes compared to the winter circulation. The saline waters of Levantine origin enter the southern Aegean mainly through the Rhodes - Karpathos Straits and move to the northwest towards the Cyclades plateau. A secondary current entering through the Kassos 

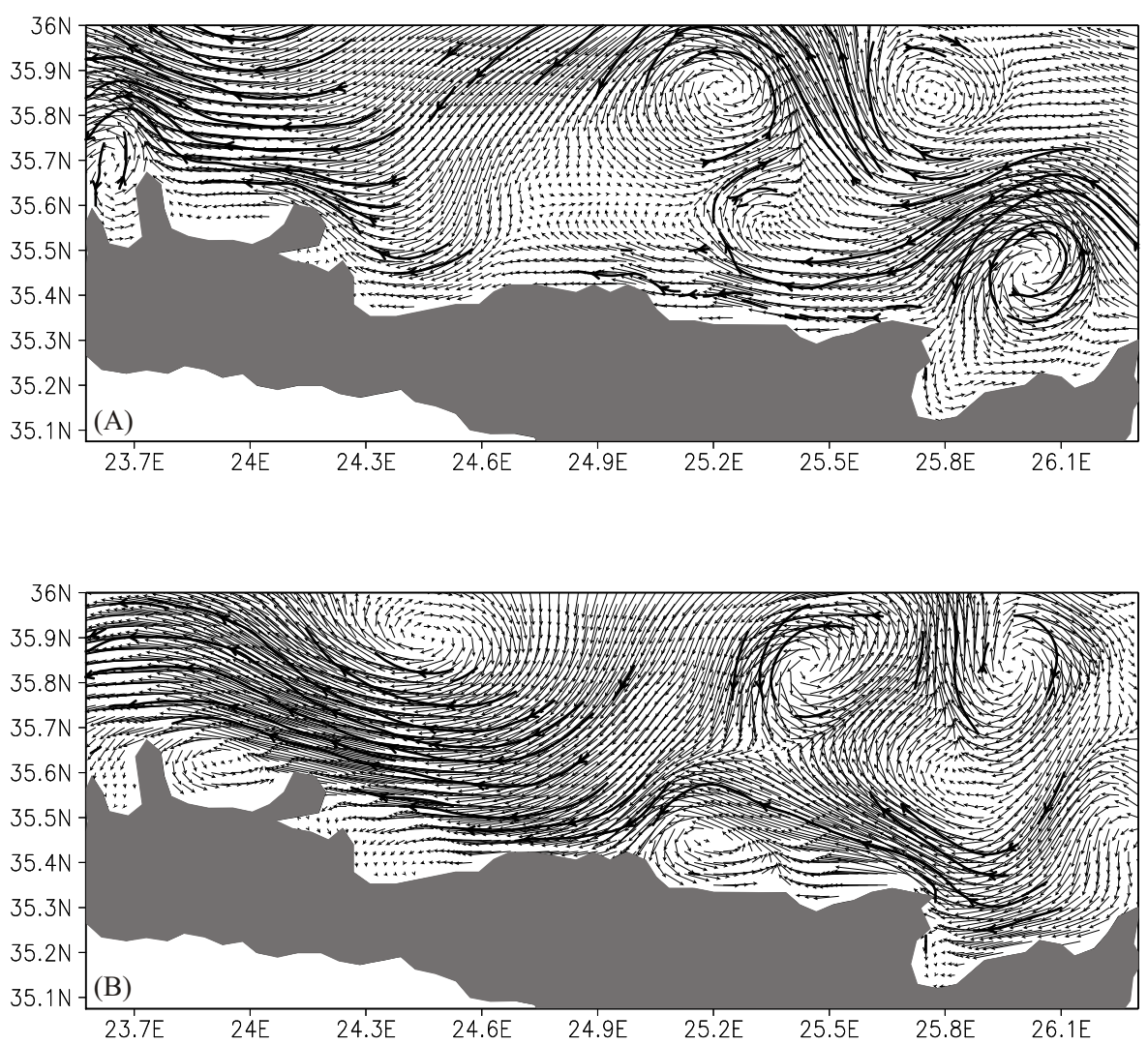

Fig. 8. (a) Winter (11-20 March) subsurface (30 m) circulation pattern for the Cretan Sea, corresponding to SI-AL run (third year). (b) Same as (a) but for summer (11-20 September).

Straits also follows the same pathway. Thus, the intense westward current at $36^{\circ} \mathrm{N}$, very evident during the winter period, is completely absent. The same happens with the northward flow entering the southern Aegean Sea along the eastern coasts of Crete during winter. As a result, the intense mesoscale activity observed during winter relaxes completely, although there is some signature of a cyclonic circulation at the eastern edge of Crete and at $25.2^{\circ} \mathrm{E}-35.8^{\circ} \mathrm{N}$. An interesting feature during this period is the existence of a southward flow at approximately $24.7^{\circ} \mathrm{E}$, emanating from the Cyclades plateau area. As it moves towards Crete, this southward flow turns to the west and exits the Aegean Sea through the Kithira-Antikithira Straits. Thus, during the summer period the intensity and the morphology of the current system to the north of Crete shows significant changes as compared to winter.

In Fig. $8 \mathrm{~b}$ the response of the Cretan Sea model to this altered situation is shown. Waters enter the modelling domain through the eastern and northern boundaries and form a westward flow along the Cretan coasts. Although this intrusion is consistent with the prominent cyclonic circulation at the eastern edge of Crete observed during winter, it has completely disappeared now and might be attributed to the altered curvature and the intensity of the inflowing westward current imposed by the ALERMO model. A series of mesoscale cyclonic/anticyclonic features is still evident inward to the northern boundary of the model.

\section{Conclusions}

This work undertakes a series of high-resolution studies of shelf processes, within the framework of MFSPP (Mediterranean Forecasting System Pilot Project). Among the various simulation experiments that took place, two main experiments were presented here. In the first one, observations from the climatological MODB data sets were objectively analysed, and along with the analysed data collected through the POEM project, set the stage for a high-resolution simulation by providing data against which model results were validated. The model results were found to be in good agreement with the observations, revealing mesoscale and smaller scale cyclonic and anticyclonic eddies interconnected by intense currents and jets. The main features of the area are a westward flow and a general cyclonic circulation pattern during the winter, and a meandering eastward flow during the summer. The appearance of MAW during the summer in the western regions of the area and its transportation further eastwards by the currents, as well as the existence of other types of water (CIW, LIW), are shown in the model results. In order to account for forcing that may originate from outside a local region, a nesting technique is adopted. Nesting 
is a means of embedding a high-resolution domain inside a lower resolution domain.

In the nesting experiment, the shelf high-resolution Cretan Sea model was one-way nested with the lower resolution regional ALERMO model, and the evolution of the flow features on the high-resolution grid was compared against the lower resolution grid. During winter the Cretan Sea circulation characteristics are controlled largely by the Levantine origin waters flowing into the Aegean Sea through the eastern Cretan Arc Straits and are revealed in the area as an intense westward current. A dipole structure of a western anticyclone and a central eastern cyclone, as well as the intense westward current, are identified both by the shelf and the regional models. The summer circulation pattern of both models exhibits significant changes compared to the winter circulation. The intense winter westward current has disappeared due to the movement of the saline waters of Levantine origin entering the southern Aegean mainly through the Rhodes - Karpathos Straits, to the northwest towards the Cyclades plateau. However, a series of mesoscale cyclonic/anticyclonic features is still shown close to the northern boundary of the models.

The Cretan Sea's nowcasting/forecasting shelf area should be the goal of a future operational forecasting system. To achieve this goal, a numerical tool was developed by nesting a high-resolution shelf model with a lower resolution regional model. This work can be viewed as a first step towards establishing a system for understanding the local and regional, persistent and transitional or recurent flow features, which, in a second step, through the development of data assimilation techniques, will lead to operational applications.

Acknowledgements. The authors would like to acknowledge, with many thanks, all the MFSPP partners whose contribution made this study possible. Also, Mrs. Margaret Eleftheriou for her help in editing this text. This work was supported by the Mediterranean Forecasting System Pilot Project MAS3-PL97-1608.

Topical Editor N. Pinardi thanks a referee for his help in evaluating this paper.

\section{References}

Balopoulos, E. T.: PELAGOS, in: Final report. Hydrodynamics and biogeochemical fluxes in the straits of the Cretan Arc, NCMR, Athens, 1-25, 1996.

Bignami, F., Marullo, S., Santoleri, R., and Schiano, M. E.: Longwave radiation budget in the Mediterranean Sea, J. Geophys. Res., 100(C2), 2501-2514, 1995.

Blumberg, A. F. and Mellor, G. L.: A description of a three-dimensional coastal ocean circulation model, in: ThreeDimensional Coastal Ocean Circulation Models, (Ed) Heaps, N. S., Washington, D.C., AGU, 1-16, 1987.

Brasseur, P., Brankart, J. M., Schoenauen, R., and Beckers, J. M.: Seasonal Temperature and Salinity Fields in the Mediterranean Sea: Climatological Analyses of an Historical Data Set, DeepSea Res., 43, 159-192, 1996.

Budyko, M. I.: Atlas of the heat balance of the Earth, Acadenic Press, San Diego California, 69 pp., 1963.
Cressman, G. P.: An operational objective analysis scheme, Mon. Wea. Rev., 87, 329-340, 1959.

Flather, R. A.: A tidal model of the northwest European continental shelf, Mem. Soc. R. Sci. Liege, 6(10), 141-164, 1976.

Georgopoulos, D., Chronis, G., Zervakis, V., Lykousis, V., Poulos, S., and Iona, A.: Hydrology and circulation in the Southern Cretan Sea during the CINCS experiment (May 1994 - September 1995), Progress in Oceanography, 46, 89-112, 2000.

Georgopoulos, D., Theocharis, D., and Zodiatis, G.: Intermediate water formation in the Cretan Sea (S. Aegean Sea), Oceanologica Acta, 12(4), 353-359, 1989.

Jaeger, L.: Monatskarten des Niederschlags fur die ganze Erde, Berichte des Deutschen Wetterdienstes, 18(139), 1-38, 1976.

Jerlov, N. G.:, Marine Optics, Elsevier Science, 231 pp., 1976.

Kondo, J.: Air-sea bulk transfer coefficients in diabatic conditions, Boudary-Layer Meteorol., 9, 91-112, 1975.

Korres, G. and Lascaratos, A.: A one-way nested, eddy resolving model of the Aegean and Levantine basins: Implementation and climatological runs, Ann. Geophysicae, this issue, 2003.

Manzella, G. M. R, Gasparini, G. P., and Astraldi, M.: Water exchange between the eastern and western Mediterranean through the Strait of Sicily, Deep-Sea Res., 35, 1021-1035, 1988.

Mellor, G. L.: User's guide for a three-dimensional, primitive equation, numerical ocean model, Princeton University, Princeton, 1991.

Mellor, G. L. and Yamada, T.: Development of a Turbulence Closure Model for Geophysical Fluid Problems, Rev. Geophys. Space Phys., 20, 851-875, 1982.

Palma, E. D. and Matano, R. P.: On the implementation of open boundary conditions for a general circulation model: the threedimensional cas, J. Geophys. Res., 105, 8605-8627, 2000.

Paulson, C. and Simpson, J.: Irradiance measurements in the upper ocean, J. Phys. Oceanogr., 7, 952-956, 1977.

Pinardi, N. and Masetti, E.: Variability of the large scale general circulation of the Mediterranean Sea from observations and modeling, Paleogeography, paleoclimatology, paleoecology, 158, 153173, 2000.

Pinardi, N., Korres, G., Lascaratos, A., Roussenov, V., and Stanev, E.: Numerical simulation of the Mediterranean Sea upper ocean circulation, Geophys. Res. Lett., 24, 425-428, 1997.

Reed, R. K.: On estimating insolation over the ocean, J. Phys. Oceanogr., 17, 854-871, 1977.

Reiniger, R. F and Ross, C. F.: A method of interpolation with application to oceanographic data, Deep-Sea Res., 9, 185-193, 1968.

Shapiro, R.: Smoothing, filtering, and boundary effects, Rev. Geophys., 8, 359-387, 1970.

Smagorinsky, J.: General circulation experiments with the primitive equations, I, The basic experiment, Mon. Weather Rev., 91, 99164, 1963.

Theocharis, A., Georgopoulos, D., and Zodiatis, G.: Late winter hydrological characteristics and circulation of the Cretan Sea (S. Aegean), EGS XIII General Assembly, Bologna, Italy, March 1988, Ann. Geophysicae, Special Issue, 70, 1988.

Theocharis, A., Balopoulos, E., Kioroglou, S., Kontoyiannis, H., and Iona, A.: A synthesis of the circulation and hydrography of the South Aegean Sea and the Straits of the Cretan Arc (March 1994 - January 1995), Progress in Oceanography, 44, 469-509, 1999.

Theocharis, A., Georgopoulos, D., Lascaratos, A., and Nittis, K.: Water masses and circulation in the central region of the Eastern Mediterranean: Eastern Ionian, South Aegean and Northwest Levantine, Deep-Sea Res. II, 40(6), 1121-1142, 1993. 